\title{
Listings lesen?
}

Soll man Listings in Zeitschriften abdrucken? Als Anregung zum Abtippen macht das wenig Sinn, kann man doch derartige Listings in elektronischer Form besser verteilen. (jur-pc hat diesen Weg in Form der Mailbox gewählt.) Und trotzdem ist die Frage damit nicht erledigt. Denn Listings können auch Gegenstand der Lektüre sein. Und wenn das stimmt, ist es angezeigt, sie genau so gedruckt vorzulegen wie andere Gegenstände der Lektüre.

Die eben "angedeutete These läßt sich in zugespitzter Form für „normale" Software vertreten: Der „Quellçode“, den ein Programmierer „schreibt“ und dessen „Autor" er ist, soll - so Design-Vorstellungen für gut strukturierte Software - „lesbar" sein. „Schreiben“, "Autor" und „lesbar": Das sind Worte, die sich' ansonsten aufi vertraute Textformen beziehen. Will man nicht äußerste Willkürlichkeit der Übertragung annehmen, so hat der Sprachgebrauch bereits sein Urteil gefällt: Software ist Text. (Wie erinnerlich haben Clapes, Lynch und Steinberg ihre juristische Beweisführung zum Urheberrechtsschutz von Programmen mit diesem Ausgangspunkt begonnen; vgl. jur-pc 1989, S. 230ffi) Obwohl man sich intellektuell von der Textqualität eines Quellcodes überzeugen kann, ist es für den nicht Programmier-Erfahrenen doch schwer, diese Einsicht anschaulich nachzuvollziehen. Deswegen sei zur Einstimmung die Lektüre des Beitrags von Oechsler in diesem Heft empfohlen, das dort vorgestellte Prolog-Programm auch im äußeren Aufoau der juristischen Vorgehensweise nahe steht. Im nächsten Heft kann die Übungslektüre dann mit der besonderen Art von "Quellcode" fortgesetzt werden, die sich in der Wissensbasis juristischer „Expertensysteme" findet. Da Günther bei dem seine Beitragsserie abschließenden Listing besondere Mühe daraufı verwandt hat, das Regel-Inventar „lesbar“ zu gestalten, dürfte sich auch für den mit einer derartigen Materie nicht von vornherein vertrauten "Leser" die Mühe des „Einlesens" lohnen. Unterzieht man sich dieser Mühe, so stellt sich nach kurzer Zeit der Eindruck ein, daß hier juristisches Wissen in „lesend" nachvollziehbarer Form vorgelegt wird. (Was daraus dann für das Urheberrecht bezogen aufidiese besondere Textsorte zu folgern ist, liegt aufi der Hand.)

Übrigens bietet das vorliegende Heft von jur-pc noch in weiterer Hinsicht Anlaß, über das Lesen nachzudenken: jur-pc wird jetzt auch aufi Diskette als Blindenausgabe publiziert.

Die Sehenden machen sich oft nicht Idar, welche Bedeutung die durch die EDV, gegebenen Möglichkeiten der Textumsetzung und Textpräsentation für Blinde haben. Deswegen wurde aus dem gegebenen Anlaß ein Schwerpunkt gebildet, der nicht nur die für Blinde verfügbare EDVFTechnik vorstellt, sondern in seinem juristischen Teil zusätzlich dokumentiert, wie man im Bereich des die Hilfsmittel für Blinde betreffenden Rechts reagiert hat. (Daß unter diesem Dokumentationsaspekt juris besonders gut abschneidet, kann vielleicht für den einen oder anderen Leser Anlaß sein, die Nutzung von juris (unter der neuen Gebührenstruktur!) in Erwägung zu ziehen.) juris ist nebenbei bemerkt - für Blinde die einzige unschwer zugängliche Quelle, die z.B. über den aktuellen Gesetzestext informiert: Das ist ein Datenbankaspekt, der vielleicht bei der einen oder anderen bisherigen Debatte rund um juris nicht gebührend gewürdigt worden ist.

.Saarbrücken, den 18.3.90

Maximilian Herberger

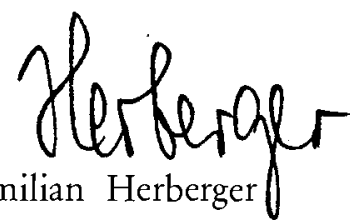

